\title{
Food protein-induced enterocolitis syndrome in children: what's known? What's new?
}

Department of Pediatrics, G. D’Annunzio University, Chieti, Italy

\section{KEY WORDS}

food protein-induced enterocolitis

syndrome; children; pathophysiology;

diagnosis; management

\section{Corresponding author}

Alessandra Scaparrotta

Department of Pediatrics

“G. D’Annunzio” University

Via dei Vestini 5, 66013 Chieti

Phone: +390871358018

Fax: +390871574831

E-mail: ale.scaparrotta@libero.it

\section{Doi}

10.23822/EurAnnACI.1764-1489.44

\begin{abstract}
Summary
Food protein-induced enterocolitis syndrome (FPIES) is an under-recognized and frequently misdiagnosed non-IgE mediated food allergy syndrome. Affected infants show gastrointestinal symptoms few hours after ingestion of the incriminating food. Pathophysiology of FPIES has not yet been clearly defined and needs further characterization. The common allergy tests are not helpful for this disorder and tests for food specific IgE are usually negative. A diagnostic oral food challenge (OFC) is the method to confirm the diagnosis of FPIES. This review summarizes what is known about epidemiology, pathophysiology, clinical characteristics and diagnosis and what's new about therapeutic options of FPIES.
\end{abstract}

\section{List of abbreviations}

APT, atopy patch testing; FPIES, food protein-induced enterocolitis syndrome; Ig, immunoglobulin; IL, interleukin; IFN, interferon; $\mathrm{MCH} 1$, major histocompatibility complex type 1; OFC, oral food challenge; PBMCs, peripheral blood mononuclear cells; Treg, regulatory T; SPT, skin-prick test; SOTI, specific oral tolerance induction; Th2, T helper 2 ; TGF- $\beta 1$, transforming growth factor- $\beta$ 1; TNF, Tumor Necrosis Factor.

\section{Introduction}

Food allergy covers a range of diseases that result from an aberrant immune response to food antigens, which can be either non-immunoglobulin (Ig) E or IgE-mediated. The non- $\mathrm{IgE}$ mediated diseases may be caused by direct $\mathrm{T}$ cell antigen response and mediated by proinflammatory cytokine (1). Food protein-induced enterocolitis syndrome (FPIES) is an uncommon, non-IgE-mediated food allergy (2).

FPIES begins in the first month of life, resolving in about 38$100 \%$ of cases at the age of 3 years (3). The initial reaction generally occurs on first or second exposure to the involved food, usually milk or soya in formula-fed infants (4). In a retrospective chart review of patients seen in the Allergy Section at The Children's Hospital of Philadelphia with International Classification of Diseases Ninth Revision code 558.3 (Allergic Gastroenteritis and Colitis) between 2007 and 2012, 43.5\% of patients who had a reaction with milk often react to soya (5). At least in Europe, FPIES caused by fish/shellfish is the most frequent solid-food FPIES (6).

The number of reports about FPIES has increased over the past few years, and reactions to new trigger foods such as green peas, 
grains, chicken, barley, rice, vegetables, poultry, fruit, oat, lentils, sweet potatoes, egg, peanuts, and turkey have been described $(2,7)$. However, less than 300 cases have been reported so far in literature and the largest series include only 44 children (8).

Breastfeeding was previously thought to be a protective factor, but some reports documented patients with FPIES who reacted to cow's milk or soya protein passed through the breast milk $(9,12)$. Food sensitization in FPIES that can occur through breast milk is, in fact, also described (13).

A link of FPIES with methicillin-resistant Staphylococcus aureus and enterotoxigenic Escherichia coli has been also described, suggesting that in some cases, enteral infections can play a role in the progress in FPIES (14).

Affected infants typically demonstrate severe gastrointestinal symptoms that usually occur within the $9^{\text {th }}$ month of life (2). The symptoms, that appear 1 to 4 hours after ingestion of the offending food, are severe protracted vomiting, pallor, diarrhea, lethargy and hypovolemic shock $(15,16)$. Additional findings consist of methemoglobinemia, increased gastric juice leukocyte levels, metabolic acidosis, neutrophilia and thrombocytosis $(17,21)$. All these symptoms and signs are not disease-specific, so FPIES is frequently misdiagnosed and treated as sepsis, surgical abdominal emergency, severe gastroenteritis or metabolic disorders (2).

Several gastrointestinal diseases in children have been attributed to immunologic reactions to food proteins (4). These reactions can involve all the gastrointestinal tract, from mouth to rectum (4).

Even though it is not easy to categorize food protein-induced gastrointestinal disorders in one notion, a consensus conference in 2000 clarified the clinical differences and pathophysiologic process involved in each of these conditions (22). These diseases can be classified as IgE mediated (oral allergy syndrome and immediate gastrointestinal hypersensitivity), non-IgE mediated (food protein-induced enterocolitis, food protein-induced proctocolitis, food protein-induced enteropathy, celiac disease) or mixed (allergic eosinophilic esophagitis, allergic eosinophilic gastritis, allergic eosinophilic gastroenterocolitis) (4).

\section{Epidemiology}

FPIES is a rare non-IgE-mediated gastrointestinal allergic condition with a mild male predominance (50-60\%) (23).

A complete estimation of FPIES epidemiology is limited by the lack of a universally accepted definition and the publication of few prospective population-based case series. Older nonpopulation-based studies reported an average of 1-15 cases per year, but recent studies have reported a number as high as 90 cases per year. The incidence of FPIES to all incriminating food was one in 10,000 infants less than 2 years of age, that closely corresponds to the Australian reported incidence of eosinophilic esophagitis in children of 0.9 per 10,000 (24).
In a recent prospective population-based study in Israel, the incidence of cow's milk FPIES was $0.34 \%$ in the first year of life (8). There is a regional variation about involved foods, rates of combined cow milk and soya FPIES, and multiple food group FPIES (23). Eczema and a family history of atopy are frequently present at diagnosis and about 1/10 infants have IgE food allergies and siblings are seldom affected $(23,25,26)$. Acute FPIES is primarily a disorder of young infants, while chronic form usually presents in neonates (23).

\section{Pathophysiology}

FPIES is a cell-mediated food hypersensitivity but its exact immune mechanism is not known $(1,2)$.

Although various immunologic alterations have been described in FPIES, little is known about its pathophysiology, and it requires further characterization. An early onset IgE-mediated reaction doesn't seem to be involved: this hypothesis is supported by negative skin prick tests (27). The involvement of antigen-specific $T$ cells and their production of proinflammatory cytokines in the control of intestinal barrier permeability has been suggested, but humoral immune responses can also be interested (4).

The best-known oral tolerance is an immune response involved in the tolerance to food antigens induced via the gut. It is associated with the production of local and systemic immunological tolerance due to induction of regulatory $\mathrm{T}$ (Treg) cells, clonal deletion and $\mathrm{T}$ cell anergy. Many data supported the role of $\mathrm{CD} 4+\mathrm{CD} 25+$ Treg cells in mediating oral tolerance against dietary antigens, by suppression of the effector $\mathrm{T}$ cells, a characteristic partly cell contact-dependent. On the other hand, also feeding experiments in mice and indirect evidence as patients with enteropathy, immune dysregulation, polyendocrinopathy, $\mathrm{X}$-linked syndrome, or X-linked autoimmunity-allergic dysregulation syndrome that lack this T-cell subset support this hypothesis $(28,29)$.

Van Sickle et al. suggested a T-cell mediated response because of the in vitro proliferation to food antigen of peripheral blood mononuclear cells (PBMCs) in patients with FPIES as compared with non-allergic controls (30).

Antigen-specific T cells seems to be involved releasing high levels of proinflammatory cytokine Tumor Necrosis Factor (TNF) $-\alpha$ that act synergistically with interferon (IFN) $-\gamma$ to increase intestinal permeability, contributing to the antigens influx into the submucosa with additional antigen-specific $\mathrm{T}$ cells activation $(4,28)$. So, an alteration in intestinal permeability related to TNF- $\alpha$ production by PBMCs characterizes gastrointestinal allergy to cow's milk $(4,28,31)$. Another study reported that lower quantity of cow's milk protein is required to induce TNF- $\alpha$ secretion from PBMCs of patients with active intestinal cow's milk allergy, as compared with patients with skin rather than 
gastrointestinal sensitivity or those whose allergy had resolved (32). Moreover, fecal TNF- $\alpha$ levels were augmented in the stool after positive cow's milk challenges in subjects with enterocolitis (33). All these studies suggest that TNF- $\alpha$ has an important function in the pathophysiology of the FPIES (27), although the precise mechanism of this disease is still uncertain.

A relative failure of expression in transforming growth factor- $\beta 1$ (TGF- $\beta 1$ ) receptor can also be involved (34). The regulatory cytokine TGF- $\beta 1$ acts protecting gut epithelial barrier from penetration of foreign antigens, stimulating extracellular matrix proteins, fibronectin and collagen synthesis and altering the expression of integrins, that enhances the binding between cells and matrix proteins. Moreover, it induces T-cell suppression. In young infants, a reduced activity of TGF- $\beta 1$ against the barrier-disrupting effect of T-cell cytokines can be involved in the pathogenesis of FPIES. Older children showed increased TGF- $\beta 1$ level after weaning, justifying the reason why FPIES is only seen in young children $(4,34,35)$. On the other hand, TGF- $\beta$ blockade also induced IFN- $\gamma$ production $(28,36)$.

So, the acute FPIES reaction appears to be related with a Th2 skewing of the T-cell cytokine production (28).

Interleukin (IL)-10 amplified expression is linked with the ingestion of the same food when tolerance is reached. So, IL-10 may exert an important function in regulating Th1 and Th2 response, especially at the gut level $(37,38)$. Conversely, IL- 4 is an inflammatory cytokine implicated in the gut immune response by blocking the induction of Foxp 3 with subsequent generation of inducible regulatory $\mathrm{T}$ cells $(28,39)$.

The hypothesis that T helper 2 (Th2) activation with high IL-4 levels can be involved in FPIES pathophysiology, while IL-10 may regulate the Th2 responses involved in the immunotolerance acquisition, was supported by an increase in T-cell IL- 4 expression and a decrease in IFN- $\gamma$ observed in an 8-month-old child with acknowledged FPIES to rice, after a positive challenge with rice; in contrast after acquisition of oral tolerance, an increase in T-cell IL-10 expression was observed after rice challenge 6 months later after a negative challenge $(28,40)$.

The potential involvement of humoral immune response in the pathophysiology of FPIES includes an increase of specific IgA and $\operatorname{IgG}$ and a decrease in specific IgG4 antibodies $(4,28,31,41)$. Some authors demonstrated an increase of milk protein-specific IgA in patients with FPIES, not associated with elevated IgG1 or IgG4 antibodies compared with controls. In fact, a lack of milk protein-specific IgG4 may have a role in FPIES, having a protective role in competing with other subclasses that could activate complement $(28,41)$.

\section{Symptoms of food protein-induced enterocolitis syndrome}

Signs and symptoms and the natural course of this disease have been explained through many reports, usually single cases or small case series $(4,15-18,25,42-47)$. The clinical features of FPIES range from mild symptoms, such as mild emesis and/ or diarrhea, to severe and potentially life-threatening clinical features.

FPIES may be divided into two forms: acute and chronic forms (48). The main characteristics in acute and chronic FPIES are shown in figure 1.

FPIES is a non-IgE-mediated reaction that usually presents with acute severe repetitive and profuse vomiting and diarrhea (sometimes bloody) within 1-3 $\mathrm{h}$ following the intake of the offending food, with subsequent dehydration and shock in $20 \%$ of the cases $(17,25,49)$. Generally, $75 \%$ of infants with FPIES are acutely ill, comprising $15-20 \%$ with hypotension in need of hospitalization (4). Additional frequent symptoms are cyanosis, pallor, lethargy and hypothermia (4).

In a recent study counting a great amount of subjects, the main clinical feature was vomiting $(100 \%)$, followed by lethargy (85\%), pallor (67\%) and diarrhea (24\%) (18). Manifestations resolve usually within $24-48 \mathrm{~h}$ of elimination of the causative food (48), even if in the early reports, up to $15-20 \%$ of children presented in a hypovolemic shock necessitating fluid resuscitation (4). Anyway, in another recent study, no case of significant hypotension was reported. In this case, all were treated with oral rehydration (8). This difference might be due to under-representation of mild FPIES due to selection bias in previous studies (4).

A recent study demonstrated a mean age of 5.5 months at initial presentation (18).

Chronic FPIES appears if the antigen is being taken regularly and it has been described in young infants fed with cow milk or soya-based formulas $(4,15,16,43)$. Symptoms usually start in the first month of life with intermittent vomiting, persistent diarrhea, poor weight gain and failure to thrive (4). This condition can evolve to acidemia and shock (4). If introduction of the involved food in the diet of the child is delayed, such as in exclusively breastfed infants, the onset of symptoms may occur at an older age (up to 9 months), even if the mother is ingesting the offending foods in her diet (4). However, there are several reports of FPIES onset subsequently early infancy (50). Elimination of the involved food should lead to fast remission of symptoms in some days. The chronic early phase may be followed by an acute phase if the antigen is eliminated from the diet for at least 2-3 days and then reintroduced, with symptoms starting about $1.5-2 \mathrm{~h}$ after intake of the offending food (15). Repetitive and severe vomiting usually takes place $1-3 \mathrm{~h}$ and diarrhea occurs 5-8 $\mathrm{h}$ after ingestion (7).

Methemoglobinemia has been reported in infants with severe reactions and acidemia. Murray and Christie described 35\% of 17 cases of PFIES with transient methemoglobinemia (51). 
Figure 1 - Comparison between acute and chronic food protein-induced enterocolitis syndrome: clinical and laboratory findings. Modified from (48).

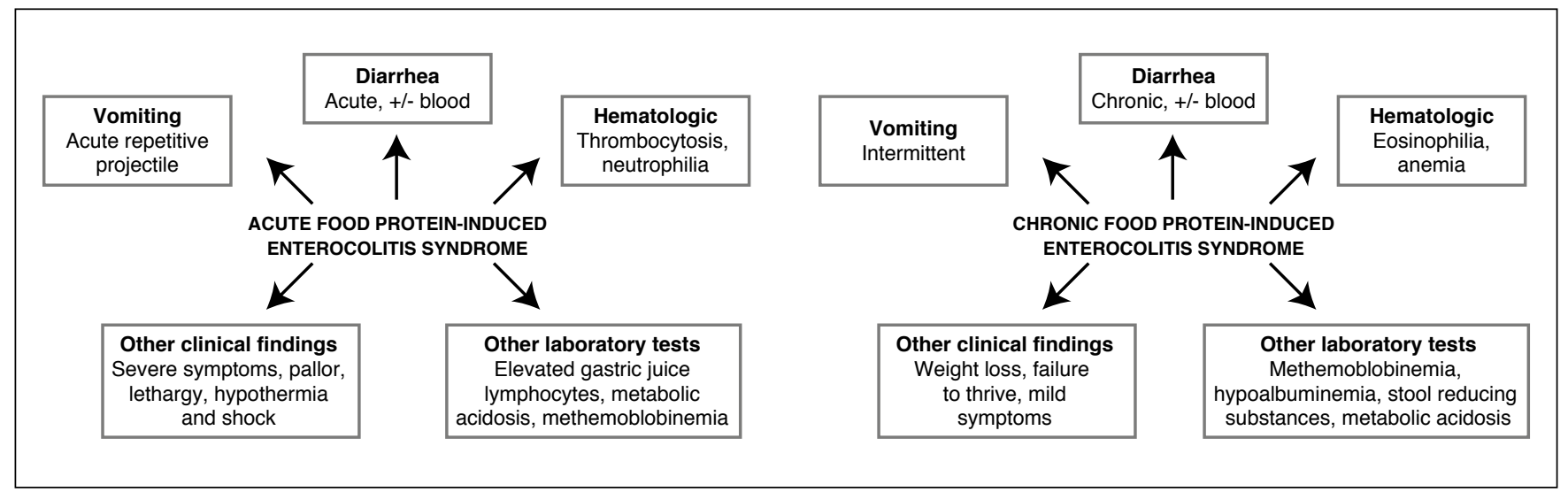

These patients appear listless and ashen-gray (4). Methemoglobinemia is due to an elevation of heme oxidation because of increased nitrates in the intestine caused by reduced catalase activity during inflammation (51).

\section{Diagnosis of food protein-induced enterocolitis syndrome}

The diagnosis of FPIES is often difficult and delayed because of the lack of classic, unequivocal, typical allergic symptoms and the absence of biomarkers $(20,52)$. Serum food-specific IgE and skin-prick test (SPT) are generally negative $(9,18,25,49)$. But some investigators observed that $4-25 \%$ of children with FPIES originally have or develop food-specific $\operatorname{IgE}(5,8,53,54)$. Patients with detectable $\mathrm{IgE}$ of the incriminating food are called atypical FPIES $(17,55)$. Atypical FPIES has been reported in older children (55) and also in adults (56), generally associated to some specific food, such as fish and shellfish ingestion.

The NIAID Food Allergy Guidelines recommend using the clinical history and oral food challenge (OFC) to diagnose FPIES (57).

Nevertheless, if medical history suggests that the children have experienced hypotensive episodes or multiple reactions to the same food, the diagnosis can be based on a history and lack of symptoms when the culprit food is removed from the alimentation (58). The original diagnostic criteria, proposed by Powell, were based on the fact that exposure to the causative food causes repetitive vomiting and/or diarrhea within $4 \mathrm{~h}$, excluding other causes for these symptoms; symptoms are restricted to the gastrointestinal tract; the removal of the causative protein from the diet of the children causes remission of symptoms; and a standardized OFC or isolated re-exposure causes typical symptoms (43). In 2013 Miceli Sopo et al. (59) suggested criteria to support the clinician to establish a diagnosis of FPIES, which consist of the following: less than 2 years of age at first episode (not mandatory); repetitive pallor, vomiting and lethargy within 2-4 h, and generally lasting less than $6 \mathrm{~h}$, after the intake of the causative food; lack of symptoms that advocate an IgE-mediated response; remission of the symptoms due to the elimination of causative food; relapse of symptoms within $2-4 \mathrm{~h}$ of re-exposure to the same trigger food.

Classic allergy testing such as prick skin testing or in vitro testing for food specific $\mathrm{IgE}$ are not useful to diagnose FPIES as they are negative.

Atopy patch testing (APT) is a useful tool for a delayed, non-IgE-mediated reaction to food. It is performed by dissolving small quantities of causative food proteins in saline and placing the mixture in aluminum Finn chambers (27). Fogg MI et al. (27) tried to establish if the APT could be able to detect the presence or absence of FPIES in nineteen infants. The results of APT and oral food challenge (OFC) were compared and used to determine specificity and sensitivity of the APT. APT predicted OFC results in 28/33 instances. 16 cases of FPIES were confirmed by OFC and in these 16 cases the APT was positive to the suspected food. The APT was found positive in 5 instances where the OFC was negative. All 12 patients with a negative APT had a negative OFC to the suspected food. So APT appears to be a promising diagnostic tool for the diagnosis of FPIES (27) Jarvinen et al. (60) evaluated APT in 38 children with FPIES and undergoing OFC. They estimated sensitivity of $11.8 \%$ and specificity of $85.7 \%$. However, to date, the diagnostic utility of this test remains still unclear (58).

Although the diagnosis of FPIES is based on clinical features, in the acute cases of FPIES, laboratory exams can document neutrophilia and thrombocytosis, peaking about $6 \mathrm{~h}$ post-ingestion, and, in the more severe cases, methemoglobinemia and meta- 
bolic acidosis can also occur. In chronic cases, hypoalbuminemia, anemia, and also eosinophilia can be present. Radiologic evaluation or other procedures can demonstrate nonspecific abnormalities. Further studies looking at the phenotypes of FPIES are required to recognize clinical subtypes, and to understand the predisposing factors for developing FPIES (48).

The majority of cases of FPIES appear in infants and resolve by school age, but FPIES can occur at any age and persist into teenage and adult years (61).

The presence of specific IgE antibodies to the trigger food defines an "atypical form" of FPIES. This is characterized by a reduced possibility of developing tolerance and a probable evolution to typical IgE-mediated hypersensitivity. Indeed, the shift from non-IgE-mediated milk-protein induced enterocolitis syndrome to IgE-mediated milk allergy has been described (62), even if it is infrequent.

\section{Differential diagnosis of food protein-induced enterocolitis syndrome}

A detailed clinical assessment associated to laboratory findings, is required to lead the clinicians to diagnose FPIES.

In acute forms of FPIES, the differential diagnosis comprises (52):

- sepsis or other infectious diseases

- acute gastrointestinal episodes

- surgical emergencies (necrotizing enterocolitis or pyloric stenosis in neonates)

- food allergies (allergic proctocolitis, anaphylaxis, IgE-mediated food allergy).

In chronic forms of FPIES, the differential diagnosis comprises (52):

- malabsorption syndromes (such as celiac disease) (63)
- metabolic disorders (amino acid metabolism disorders, organic acidemias, urea cycle defects, some inherited energy metabolism disorders)

- primary immunodeficiencies (64)

- psychosocial conditions (Munchausen by proxy syndrome, food aversion)

- neurological conditions

- infectious conditions (e.g. HIV, Salmonella, Yersinia)

- coagulation defects

- other types of non-IgE-mediated food allergy.

\section{Management of food protein-induced enterocolitis syndrome}

To date, the elimination of the causative food from the diet of the little patient is the only therapy for FPIES.

The intake of food and nutritional status should be monitored and advice on added protein, micronutrients and kcal should be provided when necessary (65).

Sicherer (50) has underlined that the management of FPIES is based on the symptoms and on recent knowledge of its immunopathogenesis that is yet incomplete. Table $\mathbf{1}$ shows the management of acute and chronic FPIES.

The treatment of acute forms of FPIES is mainly supportive with continued fluid resuscitation. Patients need monitoring until they become hemodynamically stable (35).

Intravenous fluids and steroids should be used in acute and severe forms of FPIES with profuse and repetitive vomiting, bloody and severe diarrhea, hypotension, pallor, hypotonia and lethargy (66). The role of epinephrine has still not been elucidated, and the consistency of the reports on the epinephrine usage - in treating hypotension when intravenous fluids and steroids fail $(50,67,68)$ or in cases with severe lethargy and without

Table 1 - The management of acute and chronic food protein-induced enterocolitis syndrome (FPIES) $(66,67)$.

\section{Acute FPIES}

rehydration fluids:

- in the mild form of FPIES: oral rehydration fluids

- in moderate to severe form of FPIES: intravenous fluids (20 $\mathrm{ml} / \mathrm{kg}$ boluses of isotonic saline) intravenous steroids: methylprednisolone $1 \mathrm{mg} / \mathrm{kg}$ (max 60-80 mg)

in severe form of FPIES or in case of PFIES unresponsive to fluids: vasopressors for hypotension

\section{Chronic FPIES}

removal of offending food from child's diet if dehydration: intravenous fluids

in case of cow's milk-FPIES: use soy alternative (following a supervised oral food challenge), casein hydrolysate, or elemental formula

\begin{tabular}{ll}
\hline in case of acidemia: bicarbonate & in case of acidemia: bicarbonate \\
\hline in case of methemoglobulinemia: methylene blue & in case of methemoglobulinemia: methylene blue \\
\hline
\end{tabular}


hypotension (59) - is debatable, because the studies enrolled a small number of patients without any controls. Some investigators reported the rapid resolution of symptoms (such as vomiting and lethargy) within 10-15 min after the use of ondansetron hydrochloride, a serotonin 5-HT3 receptor antagonist utilized mostly as an antiemetic, $(0.2 \mathrm{mg} / \mathrm{kg} / \mathrm{dose})$ in 5 children above 3 years of age diagnosed with FPIES, who had an adverse reaction during the OFC (69). In chronic FPIES with dehydration it is often necessary to use bicarbonate to correct acidosis and methylene blue for methemoglobulinemia, unlike acute forms in which these treatments are rarely necessary (66). The critical cases of chronic FPIES should be rehydrated with either oral or intravenous fluids, and temporary bowel rest and parenteral nutrition can be used in the most severe forms (66).

The clinical treatment of a patient with FPIES includes also 3 key points: recurrence of acute episodes for the unintentional intake of offending food; dietary introduction of at-risk foods; acquisition of tolerance with periodic re-evaluations (66).

Recurrence of acute FPIES episodes due to unintentional intake of offending food should be carefully taken into consideration. If it occurs, the patient should seek medical attention (50), but if symptoms start in the absence of medical assistance, the oral intake of fluids and steroids is recommended and it is supportive to give patients an action plan, explaining symptoms and recommending treatment of acute reactions (66).

The primary recommended managements are steroids and intravenous fluids. In mild-to-moderate cases, oral rehydration should be sufficient (66).

Regarding the dietary introduction of at-risk foods, it has been recommended not to introduce foods that cannot be tolerated (typically cereals, cow's milk, poultry and legumes) during the first year of life, in addition to that identified as offending food. Then, they can be introduced in the diet for the first time in hospital, performing an oral food challenge (66).

The third key point is the acquisition of tolerance that depends on the involved food. In fact, children with FPIES caused by cow's milk have a good chance of acquiring tolerance at the age of 18-24 months. But insufficient data are available to date for other involved foods, so that it is suggested that an OFC should be performed about 1 year after the last acute episode (66).

Future therapy will also be based on the increased understanding of pathogenesis of FPIES, on different phenotypes, and on the use of more effective management for acute episodes.

\section{New therapeutic strategies in food protein-induced enterocolitis syndrome}

To date, the elimination of the causative food from diet of the little patient is the only therapy for FPIES (70). For children with IgE-mediated cow's milk or egg allergy, instead, Specific Oral Tolerance Induction (SOTI) is one of the therapeutical op- tions (53). In addition, some children with IgE-mediated cow's milk or egg allergy may tolerate well-cooked causative food $(71,72)$. SOTI is maybe of limited benefit in FPIES cases, due to its rare persistence after 3-4 years of age. Because of FPIES is a non-IgE mediated food allergy syndrome, should not benefit from cooking of the causative food, which can decrease protein allergenicity destroying the conformational epitopes (73). In fact, a case of egg FPIES with adverse reaction after ingestion of a baked cake prepared with eggs supported this hypothesis (74). Nevertheless, Miceli Sopo et al. (70) did not confirm this theory observing that $4 / 7$ children with FPIES tolerated the wellcooked (baked) causative food.

Contrasting data about the utility of cooking causative food suggests that this aspect should be more elucidated and investigated.

If FPIES pathogenesis is only based on cell-mediated response, tolerance versus well-cooked causative food could not be possible in patients with active FPIES, as conformational epitope denaturation due to high temperature should not obstruct antigen-receptor link, as for IgE-mediated allergies (70). In fact, the recognition by $\mathrm{T}$ lymphocytes of antigenic peptides exposed (after protein degradation) on cellular surface of dendritic cells by major histocompatibility complex type $1(\mathrm{MCH} 1)$ receptors is not specific for allergen and independent from its structural conformation (75).

However, a number of factors could suggest a probable function for specific IgE in the pathogenesis of FPIES (table 2).

Several expert authors have postulated that FPIES may also be IgE-mediated (4,78). These observations, together with the observations of Miceli Sopo S. et al (70) that part of their children with FPIES tolerated the well-cooked (baked) causative food, makes the question suitable for further analysis. In addition, finding specific $\mathrm{IgE}$ for ovalbumin, that is a thermolabile egg protein, in one of their children, makes this hypothesis consistent. In addition, these authors postulate that phenotypes of FPIES mediated by specific IgE against the causative food could exist. So, it can be concluded that some of these children could tolerate the causative food if well-cooked due to the degradation of the conformational causative epitope.

\section{Conclusions}

In conclusion, FPIES is an unrecognized non-IgE-mediated food allergy usually caused by cow's milk and soya in children. Early recognition of symptoms of FPIES and removal of the offending food is imperative to prevent misdiagnosis and mismanagement of symptoms that might mimic others conditions (such as viral illness or sepsis) and lead to failure to thrive when food is chronically present in the diet.

Although there are advances in knowledge of FPIES, a better characterization of this important and often misunderstood dis- 
Table 2 - Hypothesis of probable function of specific IgE in pathogenesis of FPIES.

in the same patient, FPIES with undetectable IgE for the causative food may co-occur with food IgE-mediated allergy for other foods (76)

a number of FPIES develop to IgE-mediated gastrointestinal anaphylaxis (77)

in the literature is described a case with symptoms of a pathology similar to FPIES, seemingly not IgE-mediated, that had specific IgE detect only at duodenal site (78)

some studies report that 4-25\% of children with FPIES initially have or develop food-specific $\operatorname{IgE}(5,8,20,54)$

although some children present symptoms before $2 \mathrm{~h}$ from the intake of the causative food, the time of symptoms occurrence is generally $2 \mathrm{~h}$; it is neither distinctive for cell-mediated responses, which habitually take place later, nor of classic IgE-mediated responses; time of symptoms occurrence in FPIES appears to be intermediate between non IgE-mediated and IgE-mediated reactions (70)

ease is urgent, in order to identify biomarkers and to develop new treatment strategies.

\section{Conflict of interest}

The authors declare that they have no conflict of interest.

\section{References}

1. Gonzalez-Delgado P, Caparros E, Moreno MV, Clemente F, Flores E, Velasquez L, et al. Clinical and immunological characteristics of a pediatric population with food protein-induced enterocolitis syndrome (FPIES) to fish. Pediatr Allergy Immunol 2016; 27:269-75.

2. Sopo SM, Giorgio V, Dello Iacono I, Novembre E, Mori F, Onesimo R. A multicentre retrospective study of 66 Italian children with food protein-induced enterocolitis syndrome: different management for different phenotypes. Clin Exp Allergy 2012; 42:1257-65.

3. Chaabane M, Bidat E, Chevallier B. [A new case of food protein-induced enterocolitis syndrome]. Arch Pediatr 2010; 17:502-6.

4. Caubet JC, Nowak-Wegrzyn A. Current understanding of the immune mechanisms of food protein-induced enterocolitis syndrome. Expert Rev Clin Immunol 2011; 7:317-27.

5. Ruffner MA, Ruymann K, Barni S, Cianferoni A, Brown-Whitehorn T, Spergel JM. Food protein-induced enterocolitis syndrome: insights from review of a large referral population. J Allergy Clin Immunol Pract 2013; 1:343-9.

6. Miceli Sopo S, Monaco S, Badina L, Barni S, Longo G, Novembre E, et al. Food protein-induced enterocolitis syndrome caused by fish and/or shellfish in Italy. Pediatr Allergy Immunol 2015; 26:731-6.

7. Nowak-Wegrzyn A, Muraro A. Food protein-induced enterocolitis syndrome. Curr Opin Allergy Clin Immunol 2009; 9:371-7.

8. Katz Y, Goldberg MR, Rajuan N, Cohen A, Leshno M. The prevalence and natural course of food protein-induced enterocolitis syndrome to cow's milk: a large-scale, prospective population-based study. J Allergy Clin Immunol 2011; 127:647-53e1-3.

9. Morita H, Nomura I, Matsuda A, Saito H, Matsumoto K. Gastrointestinal food allergy in infants. Allergol Int 2013; 62:297-307.

10. Monti G, Castagno E, Liguori SA, Lupica MM, Tarasco V, Viola S, et al. Food protein-induced enterocolitis syndrome by cow's milk proteins passed through breast milk. J Allergy Clin Immunol 2011; 127:679-80.
11. Nomura I, Morita H, Hosokawa S, Hoshina H, Fukuie T, Watanabe $\mathrm{M}$, et al. Four distinct subtypes of non-IgE-mediated gastrointestinal food allergies in neonates and infants, distinguished by their initial symptoms. J Allergy Clin Immunol 2011; 127:685-8.

12. Tan J, Campbell D, Mehr S. Food protein-induced enterocolitis syndrome in an exclusively breast-fed infant-an uncommon entity. J Allergy Clin Immunol 2012; 129: 873-4.

13. Mane SK, Hollister ME, Bahna SL. Food protein-induced enterocolitis syndrome to trivial oral mucosal contact. Eur J Pediatr 2014; 173:1545-7.

14. Omata N, Ohshima Y, Yamada A, Yasutomi M, Tokuriki S, Mayumi M. A case of milk-protein-induced enterocolitis associated with enterotoxigenic E. coli and MRSA infections. Eur J Pediatr 2008; 167:683-4.

15. Powell GK. Milk- and soy-induced enterocolitis of infancy. Clinical features and standardization of challenge. J Pediatr 1978; 93:553-60.

16. Gryboski JD. Gastrointestinal milk allergy in infants. Pediatrics 1967; 40:354-62.

17. Sicherer SH, Eigenmann PA, Sampson HA. Clinical features of food protein-induced enterocolitis syndrome. J Pediatr 1998; 133:214-9.

18. Mehr S, Kakakios A, Frith K, Kemp AS. Food protein-induced enterocolitis syndrome: 16-year experience. Pediatrics 2009; 123:e459-64.

19. Leonard SA, Nowak-Wegrzyn A. Food protein-induced enterocolitis syndrome: an update on natural history and review of management. Ann Allergy Asthma Immunol 2011; 107:95-101.

20. Caubet JC, Ford LS, Sickles L, Jarvinen KM, Sicherer SH, Sampson HA, et al. Clinical features and resolution of food protein-induced enterocolitis syndrome: 10-year experience. J Allergy Clin Immunol 2014; 134:382-9.

21. Hwang JB, Song JY, Kang YN, Kim SP, Suh SI, Kam S, et al. The significance of gastric juice analysis for a positive challenge by a standard oral challenge test in typical cow's milk protein-induced enterocolitis. J Korean Med Sci 2008; 23:251-5.

22. Sampson HA, Anderson JA. Summary and recommendations: Classification of gastrointestinal manifestations due to immunologic reactions to foods in infants and young children. J Pediatr Gastroenterol Nutr 2000; 30:S87-94.

23. Mehr S, Frith K, Campbell DE. Epidemiology of food protein-induced enterocolitis syndrome. Curr Opin Allergy Clin Immunol 2014; 14:208-16. 
24. Cherian S, Smith NM, Forbes DA. Rapidly increasing prevalence of eosinophilic oesophagitis in Western Australia. Arch Dis Child 2006; 91:1000-4.

25. Nowak-Wegrzyn A, Sampson HA, Wood RA, Sicherer SH. Food protein-induced enterocolitis syndrome caused by solid food proteins. Pediatrics 2003; 111:829-35.

26. Shoda T, Isozaki A, Kawano Y. Food protein-induced gastrointestinal syndromes in identical and fraternal twins. Allergol Int 2011; 60:103-8.

27. Fogg MI, Brown-Whitehorn TA, Pawlowski NA, Spergel JM. Atopy patch test for the diagnosis of food protein-induced enterocolitis syndrome. Pediatr Allergy Immunol 2006; 17:351-5.

28. Scaparrotta A, Di Pillo S, Consilvio NP, Attanasi M, Cingolani A, Rapino D, et al. Usefulness of Atopy Patch Test on a child with milk protein-induced enterocolitis syndrome: a case report. Int J Immunopathol Pharmacol 2013; 26:795-800.

29. Karlsson MR, Rugtveit J, Brandtzaeg P. Allergen-responsive $\mathrm{CD} 4+\mathrm{CD} 25+$ regulatory $\mathrm{T}$ cells in children who have outgrown cow's milk allergy. J Exp Med 2004; 199:1679-88.

30. Van Sickle GJ, Powell GK, McDonald PJ, Goldblum RM. Milkand soy protein-induced enterocolitis: evidence for lymphocyte sensitization to specific food proteins. Gastroenterology 1985; 88:1915-21.

31. McDonald PJ, Goldblum RM, Van Sickle GJ, Powell GK. Food protein-induced enterocolitis: altered antibody response to ingested antigen. Pediatr Res 1984; 18:751-5.

32. Benlounes N, Dupont C, Candalh C, Blaton MA, Darmon N, Desjeux JF, et al. The threshold for immune cell reactivity to milk antigens decreases in cow's milk allergy with intestinal symptoms. J Allergy Clin Immunol 1996; 98:781-9.

33. Majamaa $H$, Miettinen A, Laine S, Isolauri E. Intestinal inflammation in children with atopic eczema: faecal eosinophil cationic protein and tumour necrosis factor-alpha as non-invasive indicators of food allergy. Clin Exp Allergy 1996; 26:181-7.

34. Chung HL, Hwang JB, Park JJ, Kim SG. Expression of transforming growth factor beta1, transforming growth factor type I and II receptors, and TNF-alpha in the mucosa of the small intestine in infants with food protein-induced enterocolitis syndrome. J Allergy Clin Immunol 2002; 109:150-4.

35. Coates RW, Weaver KR, Lloyd R, Ceccacci N, Greenberg MR. Food protein-induced enterocolitis syndrome as a cause for infant hypotension. West J Emerg Med 2011; 12:512-4.

36. Jarry A, Bossard C, Bou-Hanna C, Masson D, Espaze E, Denis MG, et al. Mucosal IL-10 and TGF-beta play crucial roles in preventing LPS-driven, IFN-gamma-mediated epithelial damage in human colon explants. J Clin Invest 2008; 118:1132-42.

37. Levings MK, Roncarolo MG. T-regulatory 1 cells: a novel subset of CD4 T cells with immunoregulatory properties. J Allergy Clin Immunol 2000; 106(1Pt 2):S109-12.

38. Asseman C, Powrie F. Interleukin 10 is a growth factor for a population of regulatory T cells. Gut 1998; 42:157-8.

39. Cardoso CR, Provinciatto PR, Godoi DF, Ferreira BR, Teixeira G, Rossi MA, et al. IL-4 regulates susceptibility to intestinal inflammation in murine food allergy. Am J Physiol Gastrointest Liver Physiol 2009; 296:G593-600.

40. Mori F, Barni S, Cianferoni A, Pucci N, de Martino M, Novembre E. Cytokine expression in CD3+ cells in an infant with food protein-induced enterocolitis syndrome (FPIES): case report. Clin Dev Immunol 2009; 2009:679381.
41. Shek LP, Bardina L, Castro R, Sampson HA, Beyer K. Humoral and cellular responses to cow milk proteins in patients with milk-induced IgE-mediated and non-IgE-mediated disorders. Allergy 2005; 60:912-9.

42. Powell GK. Enterocolitis in low-birth-weight infants associated with milk and soy protein intolerance. J Pediatr 1976; 88:840-4.

43. Powell GK. Food protein-induced enterocolitis of infancy: differential diagnosis and management. Compr Ther 1986; 12:28-37.

44. Hojsak I, Kljaic-Turkalj M, Misak Z, Kolacek S. Rice protein-induced enterocolitis syndrome. Clin Nutr 2006; 25:533-6.

45. Gray HC, Foy TM, Becker BA, Knutsen AP. Rice-induced enterocolitis in an infant: $\mathrm{TH} 1 / \mathrm{TH} 2$ cellular hypersensitivity and absent IgE reactivity. Ann Allergy Asthma Immunol 2004; 93:601-5.

46. Levy Y, Danon YL. Food protein-induced enterocolitis syndrome-not only due to cow's milk and soy. Pediatr Allergy Immunol 2003; 14:325-9.

47. Cavataio F, Carroccio A, Montalto G, Iacono G. Isolated rice intolerance: clinical and immunologic characteristics in four infants. J Pediatr 1996; 128:558-60.

48. Mane SK, Bahna SL. Clinical manifestations of food protein-induced enterocolitis syndrome. Curr Opin Allergy Clin Immunol 2014; 14:217-21.

49. Monti G, Viola S, Tarasco V, Lupica MM, Cosentino V, Castagno E. A case of severe allergic reaction to cooked potato. Acta Paediatr 2011; 100:e236-8.

50. Sicherer SH. Food protein-induced enterocolitis syndrome: case presentations and management lessons. J Allergy Clin Immunol 2005; 115:149-56.

51. Murray KF, Christie DL. Dietary protein intolerance in infants with transient methemoglobinemia and diarrhea. J Pediatr 1993; 122:90-2.

52. Fiocchi A, Claps A, Dahdah L, Brindisi G, Dionisi-Vici C, Martelli A. Differential diagnosis of food protein-induced enterocolitis syndrome. Curr Opin Allergy Clin Immunol 2014; 14:246-54.

53. Calvani M, Giorgio V, Miceli Sopo S. Specific oral tolerance induction for food. A systematic review. Eur Ann Allergy Clin Immunol 2010; 42:11-9.

54. Nowak-Wegrzyn A. Food protein-induced enterocolitis syndrome and allergic proctocolitis. Allergy Asthma Proc 2015; 36:172-84.

55. Hwang JB. Is This Symptom Even a Food Allergy?: Clinical Types of Food Protein-induced Enterocolitis Syndrome. Pediatr Gastroenterol Hepatol Nutr 2014; 17:74-9.

56. Fernandes BN, Boyle RJ, Gore C, Simpson A, Custovic A. Food protein-induced enterocolitis syndrome can occur in adults. J Allergy Clin Immunol 2012; 130:1199-200.

57. Boyce JA, Assa'ad A, Burks AW, Jones SM, Sampson HA, Wood RA, et al. Guidelines for the Diagnosis and Management of Food Allergy in the United States: Summary of the NIAID-Sponsored Expert Panel Report. J Allergy Clin Immunol 2010; 126:1105-18.

58. Feuille E, Nowak-Wegrzyn A. Definition, etiology, and diagnosis of food protein-induced enterocolitis syndrome. Curr Opin Allergy Clin Immunol 2014; 14:222-8.

59. Miceli Sopo S, Greco M, Monaco S, Tripodi S, Calvani M. Food protein-induced enterocolitis syndrome, from practice to theory. Expert Rev Clin Immunol 2013; 9:707-15.

60. Jarvinen KM, Caubet JC, Sickles L, Ford LS, Sampson HA, Nowak-Wegrzyn A. Poor utility of atopy patch test in predicting tolerance development in food protein-induced enterocolitis syndrome. Ann Allergy Asthma Immunol 2012; 109:221-2. 
61. Leonard SA, Nowak-Wegrzyn A. Food Protein-Induced Enterocolitis Syndrome. Pediatr Clin North Am 2015; 62:1463-77.

62. Banzato C, Piacentini GL, Comberiati P, Mazzei F, Boner AL, Peroni DG. Unusual shift from IgE-mediated milk allergy to food protein-induced enterocolitis syndrome. Eur Ann Allergy Clin Immunol 2013; 45:209-11.

63. Husby S, Koletzko S, Korponay-Szabo IR, Mearin ML, Phillips A, Shamir R, et al. European Society for Pediatric Gastroenterology, Hepatology, and Nutrition guidelines for the diagnosis of coeliac disease. J Pediatr Gastroenterol Nutr 2012; 54:136-60.

64. Guerrerio AL, Frischmeyer-Guerrerio PA, Lederman HM, Oliva-Hemker M. Recognizing gastrointestinal and hepatic manifestations of primary immunodeficiency diseases. J Pediatr Gastroenterol Nutr 2010; 51:548-55.

65. Venter C, Groetch M. Nutritional management of food protein-induced enterocolitis syndrome. Curr Opin Allergy Clin Immunol 2014; 14:255-62.

66. Miceli Sopo S, Dello Iacono I, Greco M, Monti G. Clinical management of food protein-induced enterocolitis syndrome. Curr Opin Allergy Clin Immunol 2014; 14:240-5.

67. Leonard SA, Nowak-Wegrzyn A. Clinical diagnosis and management of food protein-induced enterocolitis syndrome. Curr Opin Pediatr 2012; 24:739-45.

68. Jarvinen KM, Nowak-Wegrzyn A. Food protein-induced enterocolitis syndrome (FPIES): current management strategies and review of the literature. J Allergy Clin Immunol Pract 2013; $1: 317-22$.

69. Holbrook T, Keet CA, Frischmeyer-Guerrerio PA, Wood RA. Use of ondansetron for food protein-induced enterocolitis syndrome. J Allergy Clin Immunol 2013; 132:1219-20.
70. Miceli Sopo S, Buonsenso D, Monaco S, Crocco S, Longo G, Calvani $M$. Food protein-induced enterocolitis syndrome (FPIES) and well cooked foods: a working hypothesis. Allergol Immunopathol (Madr). 2013; 41:346-8.

71. Nowak-Wegrzyn A, Bloom KA, Sicherer SH, Shreffler WG, Noone $\mathrm{S}$, Wanich N, et al. Tolerance to extensively heated milk in children with cow's milk allergy. J Allergy Clin Immunol 2008; 122:342-7.

72. Lemon-Mule H, Sampson HA, Sicherer SH, Shreffler WG, Noone S, Nowak-Wegrzyn A. Immunologic changes in children with egg allergy ingesting extensively heated egg. J Allergy Clin Immunol 2008; 122:977-83.

73. Nowak-Wegrzyn A, Fiocchi A. Rare, medium, or well done? The effect of heating and food matrix on food protein allergenicity. Curr Opin Allergy Clin Immunol 2009; 9:234-7.

74. Caubet JC, Nowak-Wegrzyn A. Food protein-induced enterocolitis to hen's egg. J Allergy Clin Immunol 2011; 128:1386-8.

75. Godfrey DI, Rossjohn J, McCluskey J. The fidelity, occasional promiscuity, and versatility of $\mathrm{T}$ cell receptor recognition. Immunity 2008; 28:304-14.

76. Zapatero Remon L, Alonso Lebrero E, Martin Fernandez E, Martinez Molero MI. Food-protein-induced enterocolitis syndrome caused by fish. Allergol Immunopathol (Madr) 2005; 33:312-6.

77. Onesimo R, Dello Iacono I, Giorgio V, Limongelli MG, Miceli Sopo S. Can food protein induced enterocolitis syndrome shift to immediate gastrointestinal hypersensitivity? A report of two cases. Eur Ann Allergy Clin Immunol 2011; 43:61-3.

78. Lin XP, Magnusson J, Ahlstedt S, Dahlman-Hoglund A, Hanson $\mathrm{LL}$, Magnusson $\mathrm{O}$, et al. Local allergic reaction in food-hypersensitive adults despite a lack of systemic food-specific IgE. J Allergy Clin Immunol 2002; 109:879-87. 